\title{
'Outdooring' the Historical Corpus of English in Ghana
}

\author{
THORSTEN BRATO
}

\author{
Insights from the compilation of a historical corpus of New \\ English
}

\section{Introduction}

Over the last 30 years there has been an upsurge in research and theorising on postcolonial Englishes. Beginning with Kachru's (1985) Three Circles model, more recently the focus has shifted to models focusing on identity construction and historical developments (Schneider, 2007), central and peripheral varieties and their spheres of influence (Mair, 2013), and those aiming to provide a more integrated approach to postcolonial and nonpostcolonial Englishes (Buschfeld \& Kautzsch, 2017). Dedicated corpora such as the International Corpus of English (ICE; Greenbaum, 1991) and the Corpus of Global Web-based English (GloWbe; Davies \& Fuchs, 2015) have been designed to allow for a synchronic comparison of Englishes around the world and have since been widely used to study variation on the different levels of linguistic description within and across varieties. Recently, ICE corpora have also been used to test assumptions laid out by Schneider (2007), e.g. by comparing data from ICE corpora of varieties which have progressed to different phases (Mukherjee \& Gries, 2009) or by taking an apparent-time approach to test developments within one variety (Fuchs \& Gut, 2015).

It is only recently that scholars have begun compiling historical and diachronic corpora of postcolonial Englishes to describe and explain the linguistic history of these varieties in real time. One such corpus is the Historical Corpus of English in Ghana (HiCE Ghana), a 600,000 wordcorpus of Ghanaian English (GhE) from the period 1966-1975. The corpus was compiled with the same basic design as the written-printed sections of the Ghanaian component of ICE to uncover how GhE has changed over the last two generations.
In the following discussion, I will first summarise the sociolinguistic history of Ghana and its place in the Dynamic Model and will address where the model falls short in the Ghanaian context. I will then describe the motivation behind and challenges in the compilation of HiCE Ghana. The paper is rounded off with an illustration of some key features that can be studied using the corpus and examples of how GhE has changed over 50 years regarding lexis and grammar.

\section{English in Ghana}

Schneider (2007) suggest that as a variety develops it goes through five incremental stages based on changes in the identity constructions of the British settlers (STL) and the indigenous (IDG) population. Following Huber (2014: 87-90), the first phase of English in the Gold Coast (as Ghana was known until independence in 1957),

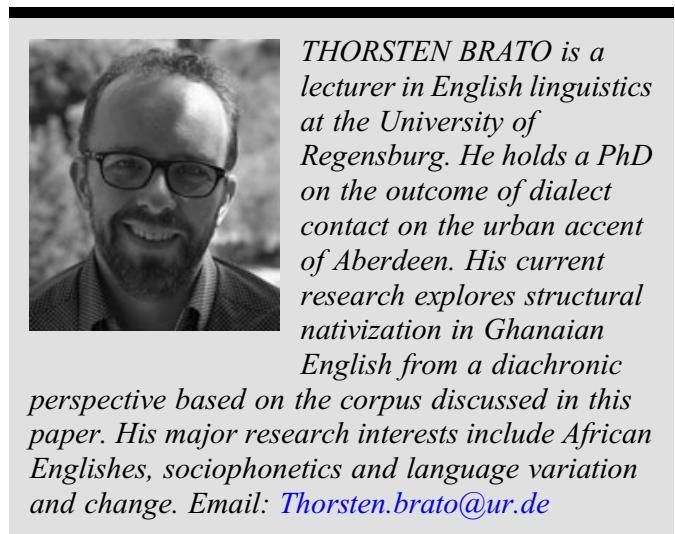


referred to as foundation, can be traced to the year 1632, when English traders first set up a permanent post on the coast near Kormantin, followed by further trading posts built over the next couple of decades. The initial years were characterised by trade between equal partners. No territorial claims were made by the British and overall the situation was rather friendly. The role of English in the indigenous population was insignificant. Only very few locals learned the language, mainly in schools located at or near the trading posts.

The colonisation of the country began in 1844 and marks the onset of the second phase, exonormative stabilisation. Linguistically, this phase is still characterised by the orientation towards the British norm, but more Africans now learned English because the colonial government needed them for administrative purposes. As the Gold Coast was an exploitation colony the number of British in the country at any time was extremely low and its population constantly changing (cf. Huber, 2014 for a discussion), the STL strand in Schneider's terms was basically missing in the country. For this reason, the linguistic impact of those Africans who spoke English at the time must not be underestimated. While the actual number of speakers of English compared to the rest of the local population was still low overall, they were the ones who filled the key positions in the political, administrative and social spheres. Despite the exonormative linguistic norm orientation, the English spoken and written by this group will have exerted a major influence on those learning English at a later point in time (also cf. Brato, in prep.).

The onset of the third phase - nativization - is the declaration of independence in 1957. This phase is characterised by large-scale linguistic change as the indigenous population transforms the language on all linguistic levels and makes it their own. These changes are most easily perceived in pronunciation, but of course there is also heavy linguistic borrowing as well as transfer of grammatical structures from local languages and the creation of linguistic preferences and variants that are peculiar to a country (Schneider, 2007: 40-8)

Phase 4 -endonormative stabilization - among other things is characterised by the change of orientation towards and the acceptance of a local model of English rather than looking towards the old, British norm, codification by means of dictionaries and literary creativity.

Huber (2014: 90) claims that Ghana falls between phases 3 and 4 . On the phonological level we can identify a few features that set
Ghanaians apart from other West Africans (Simo Bobda, 2000) and there are first attempts at codifying the language (cf. e.g. the dictionaries by Kirby, 1998, Dako, 2003 and Blench, 2006). There is also a vibrant scene of Ghanaian writers who publish in English. Furthermore, the literacy rate in English has greatly expanded over the last 50 years from about 22\% in the 1960s (cf. Sey, 1973: 1) of the adult population to about $67 \%$ in 2010 (Ghana Statistical Service, 2012: 6). ${ }^{1}$

\section{Historical and diachronic ${ }^{2}$ corpora of New Englishes and the compilation of HiCE Ghana}

There is a good body of research on the historical developments of postcolonial varieties such as the US (Schneider, 2007: 251-308) or New Zealand (Gordon, Maclagan \& Hay, 2007). At the same time, there is still a paucity of empirical, corpus-based studies of these developments in most Asian and African varieties. It is only recently that scholars have shifted their attention to the diachronic study of these Englishes. For example, a study by van Rooy \& Piotrowska (2015) reports change in the progressive in Black South African English based on a corpus of newspaper articles from the 1880 s to early 2010 s. Borlongan \& Dita (2015) look at predicates in Philippine English by comparing data from the Phil-Brown corpus containing data from the 1960s modelled on the design of the original Brown corpus (Francis \& Kučera, 1964) and ICE-Phil, the Philippine component of ICE from the 1990s.

Diachronic corpora employing the Brown design are currently compiled for Hong Kong and Singapore English (Biewer et al., 2014). They will provide snapshots of the linguistic developments in these varieties around 1930, 1960, 1990 and 2010. The advantage of these corpora lies in the direct comparability with contemporary British and American English, which allows to trace both synchronic differences across and diachronic developments in and between longestablished and new varieties of Englishes.

In the compilation of HiCE Ghana I took a somewhat different approach because of both theoretical and methodological reasons. The research goal is to illustrate in real time how one variety of English has developed over its nativization phase. Therefore my research questions include the following: Does GhE proceed as proposed by Schneider (2007)? Are there systematic deviations from the model? (How) does the virtual absence of 
an STL strand influence the linguistic developments? Are there other factors that influence or have influenced the linguistic developments of GhE, particularly those which are difficult to capture relying only on the Dynamic Model (cf. Buschfeld \& Kautzsch, 2017)?

An initial idea was to also create a diachronic corpus, taking 200,000-word snapshots of the variety at roughly ten-year intervals from 1960-62 to 2000-02 following either the Brown or ICE (written-printed) design. However, this approach was not feasible. There is a severe lack of available material for the first time frame, probably due to the small potential readership and more pressing political and developmental issues. Just how small the number of books and other material is, can be illustrated by this quotation from Apponsah (1968: 4): '[I]n 1966, Ghana produced a total of 225 books and pamphlets.' Of this figure we must deduct publications in Ghanaian languages, which further decreases the figure. Except for newspaper articles, these problems were also encountered for the 197072 period. In addition, over the whole time frame there is a strong bias towards the social sciences and humanities, whereas local publications in the natural sciences and technology are rare.

In the end, the decision was taken to compile a 600,000 -word corpus of GhE that would be large enough for a synchronic analysis of a historical state of the variety as well as diachronic, real time comparisons with the written-printed sections of ICE Ghana. The design was to follow that of ICE, i.e. I also included text samples of approximately 2,000 words, the authors had to be Ghanaian and have had at least their primary and secondary education in the country. Furthermore, only texts that were also published in Ghana were included to minimise effects of non-local editing of the material. Also, the corpus was to be larger than the 300,000 words that make up the writtenprinted categories of ICE as it was deemed too small to find more than anecdotal evidence for many lower-frequency lexical items or grammatical features. While this of course is also true for ICE Ghana, here we can resort to the GloWbE corpus (Davies \& Fuchs, 2015) if we want to check whether these items occur today.

Some additional modifications regarding corpus design were made for HiCE Ghana. While it may have been advisable to just double the number of texts or words per subcategory of ICE, this proved to be not feasible with the available data. Even after extending the period from which to include texts from 1970-1972 to 1966-1975 it was sometimes almost impossible to fill some of the subcategories to any substantial level (see Table 1 for a summary of the corpus designs and word figures for the two corpora). This was especially true for both the academic and popular Technology and Natural Sciences categories, which in addition are also not as balanced as I would have hoped for. This is because the clear majority of texts in these categories come from only three journals, of which two are mainly devoted to agriculture. A category that was comparatively easy to fill was Academic-Social Sciences, in which there is a good body of available material from various sources.

For this reason, the academic and popular writing categories are only 50\% larger in HiCE Ghana compared to ICE. Press reports were readily available, so I decided to slightly increase and further break down this category to better balance the sample and reflect the approximate distribution found. In a similar fashion, administrative writing was broken down into government and non-government and creative writing into novels and stories. I also decided to strongly increase the opinion category and introduce a new subcategory Letters to the editor, which is rather substantial in HiCE Ghana at 50,000 words. As it was not viable to include nonprinted material in HiCE Ghana, I felt that these letters would come as close as possible to a less formal writing style. In this way, I could include far more writers from different parts of the country and - at least to some degree - the lower strata of the population. To match the two corpora, I added a small number of letters to the editor to the ICE corpus as well.

The corpus design of HiCE Ghana is a compromise on some levels. Even at 600,000 words the corpus is small by today's standards and as will be seen below this, of course, will bear directly on what kinds of research we can carry out with it. Not matching the ICE categories in size or a multiple thereof directly will mean that the results may be somewhat obscured and difficult to interpret. But overall, the advantages strongly outweigh the shortcomings.

\section{Initial findings from HiCE Ghana and ICE Ghana}

Schneider (2007: 78-82) shows that postcolonial Englishes go through several stages of lexical expansion as they progress along the continuum. In the initial stages these will mainly be borrowings to describe the local flora and fauna or cultural items and practices. As a variety proceeds to the nativization phase, other word-formation processes 
Table 1: Comparison of the corpus designs and word figures of HiCE Ghana and ICE Ghana

\begin{tabular}{|c|c|c|c|}
\hline Category & & HiCE Ghana & ICE Ghana \\
\hline \multirow[t]{5}{*}{ Academic Writing } & & 120,000 & 80,000 \\
\hline & Humanities & 30,000 & 20,000 \\
\hline & Social science & 30,000 & 20,000 \\
\hline & Natural science & 30,000 & 20,000 \\
\hline & Technology & 30,000 & 20,000 \\
\hline \multirow[t]{5}{*}{ Popular Writing } & & 120,000 & 80,000 \\
\hline & Humanities & 30,000 & 20,000 \\
\hline & Social science & 30,000 & 20,000 \\
\hline & Natural science & 30,000 & 20,000 \\
\hline & Technology & 30,000 & 20,000 \\
\hline \multirow[t]{5}{*}{ Press reportage } & & 100,000 & 40,000 \\
\hline & Political & 50,000 & \\
\hline & Cultural & 10,000 & \\
\hline & Regional & 20,000 & \\
\hline & Sports & 20,000 & \\
\hline \multirow[t]{4}{*}{ Instructional Writing } & & 80,000 & 40,000 \\
\hline & Administrative (Government) & 20,000 & 20,000 \\
\hline & Administrative (non-Government) & 20,000 & \\
\hline & Skills \& Hobbies & 40,000 & 20,000 \\
\hline \multirow[t]{3}{*}{ Opinion } & & 100,000 & 30,000 \\
\hline & Press editorials & 50,000 & 20,000 \\
\hline & Letters to the editor & 50,000 & 10,000 \\
\hline \multirow[t]{3}{*}{ Creative writing } & & 80,000 & 40,000 \\
\hline & Novels & 40,000 & \\
\hline & Stories & 40,000 & \\
\hline Total & & 600,000 & 310,000 \\
\hline
\end{tabular}

will take over as being more important, most notably derivation, compounding and semantic shifts. If they become established in a variety they are often referred to as -isms, e.g. Scotticisms, Indianisms or Nigerianisms. In the Ghanaian context they have been labelled Ghanaianisms and are defined by Dako (2001: 23) as 'lexical items of both English and local origin that are peculiar to the English spoken and written in Ghana. [ ... ] Ghanaianisms have their origin in Ghana, formerly the Gold Coast and the Northern Territories, and are peculiar to Ghanaian usage.' There is a fairly comprehensive body of research on this topic, including a book chapter by Sey (1973), who lists some 300 Ghanaianisms of English origin, and more recent work by Dako (2001, 2003), who provides a 2,500-entry glossary of items of English, Ghanaian, foreign and 'hybrid' (i.e. combinations of the above) origin, and additional dictionaries by Kirby (1998) and Blench (2006). In total, some 4,000 Ghanaianisms have been documented so far.

One of the best-known Ghanaianisms, which is even listed in the OED, ${ }^{3}$ is the concept of outdooring, which refers to the cultural practice that after a child is born it is brought out of the house and presented to the relatives and neighbours for the first time. This meaning is illustrated in an example 
from HiCE Ghana in (1) and from ICE Ghana in (2).

(1) The tradition of outdooring has taken such firm roots in our society that everybody is outdoored on the eighth day after birth. (HiCE-PopHum008)

(2) It was all fun and joy when Morning Show supremo and TV personality, Kwami Sefa Kayi and his wife Ewura Adwoa (Raj), outdoored their baby in the presence of friends and family at the couple's residence on the Spintex Road in Accra. (ICE-GH $\mathrm{r}={ }^{\prime} \mathrm{W} 2 \mathrm{C}-002 \# 42: 5$ ')

There are two word-formation processes at work here. First the adjective outdoor has been converted to the verb to outdoor and in a second step there has been a semantic shift. There is, however, a second, presumably later, semantic shift that so far seems to have gone unnoticed by commentators. Hereby, the meaning of outdooring is extended to 'present something (not only babies or human beings for that matter) in public for the first time.' This meaning has been established at least as far back as the 1960s as is shown by example (3). It can also be found in ICE Ghana (4).

(3) The band, which has just returned home after a successful tour of the Ivory Coast, outdoored the Asiko [a dance] at a party they held for the Press at the YWCA, last week-end. (HiCE-PrCul002)

(4) On April 15, a lunch was held at La Palm Beach Hotel in Accra during which a book on the life of Mama Christie entitled 'A Phenomenal Woman' was outdoored by Reverend Sam Kuranchie Ankrah of Royal House Chapel International. (ICE-GH $\left.r={ }^{\prime} W 2 C-002 \# 102: 9 '\right)$

In cases like these, in which the token numbers are low (there are only 15 tokens of outdoor and its word forms for both verb and noun with either the old or new shifted meaning in HiCE Ghana and three tokens in ICE Ghana), we can turn to the GloWbE corpus to test our assumptions. A quick look at the output for outdoor shows that the new meanings are now deeply entrenched in the vocabulary of Ghanaians. In fact, they even occur much more frequently than those for the traditional meaning, which incidentally is most frequent as an adjectival or nominal form outdooring as in (5) or as the modifier in a compound as in (6). Looking at how the word is used as a verb provides a very different picture, though. Here, we see that it can be applied to basically every context, as in (7) and (8) and that these new meanings are more common, hence also the title of the current paper.

(5) In most Ghanaian communities, birth is marked by a simple ceremony which is called 'outdooring' and/or 'Naming.' It is called an 'outdooring' because on that day the baby who until then has been kept out of public view is brought out. (GloWbE GH G)

(6) Let us discuss the rites performed by some communities during their naming or outdooring ceremonies. (GloWbE GH G)

(7) Mobile telephone network, Tigo has outdoored the first ever unlimited time-based internet prepaid service at a short ceremony in Accra. (GloWbE GH G)

(8) The Ghana Oil Company (GOIL) has outdoored its rejuvenated brand identity at a ceremony held at the company's new GOIL filling station on the La beach road in Accra last Friday. (GloWbE GH G)

One other example for a semantic shift that has so far not been mentioned in the research literature is inmate. The most common meaning of a person serving a prison sentence is also found frequently in GhE. There is, however, an additional meaning 'any other people in the house; the tenants or neighbours living in the same house' as can be seen in (9) and (10) taken from HiCE Ghana.

(9) It is customary for the guest to greet the host and the inmates as well. (HiCE-SkiHob001)

(10) Their landlord and inmates had very great respect for them. (HiCE-Novel018)

No instances were found in ICE Ghana and a search in GloWbE also returned only few results, such as in (11).

(11) Any person who? \# (a) when required to give his name and address under section 16 , fails to do so or gives a false name or address; or \# (b) not being an inmate, servant or lodger $[\ldots]$ (GloWbE GH G)

With compounds, we need to distinguish between those in which only English items are used and those in which an English and Ghanaian item are combined. There is, for example, the bookman or lorry park overseer (12). Both concepts are probably unknown to non-Ghanaians, but essentially mean the same, namely a person who is responsible for managing the ticket sales at a bus station, in GhE referred to as a lorry park (13). 
(12) THE Accra-Tema City Council is to re-engage all lorry park overseers (bookmen). (HiCE-PrReg-025)

(13) Some of those who had somehow finished their purchases rushed to the lorry park hoping to reach home before the rain started. (ICE-GH r='W2 F-005\#11:1')

Hybrid compounds are overall less common, but often are highly salient and well-known, as in Akwasidae festival, an Akan celebration that takes place on a Sunday every 40 days as in (14) or kontomire soup, a popular dish made of leaves of the coconut (15). In this example we also find fufu, a borrowing describing the staple food of Ghana made of pounded yam and light soup, which indicates a meat and vegetable broth.

(14) The last Akwasidae festival of the Akan year is set aside for the celebration of Adae Kese. (ICE-GH r='W2B-012\#29:1')

(15) Fufu is served with soups of varying kinds. It can be served with plain light soup, palmnut soup, groundnut soup, or kontomire soup.

The third group of innovative word-formation processes is that of derivation by means of affixation, which, however, is far from common in the data from both corpora. Better-known examples include the concepts for enthroning and dethroning chiefs, which in the southern areas of Ghana sit on a stool and in the northern parts wear animal skins as a sign of power. Therefore, we find that chiefs may be enstooled (Sey, 1973: 80) or deskinned as in (16) and (17).

(16) In some years of his life a chief may be destooled and re-instated by the same people who may re-destool him if he is found to have changed the ways that had led to his destoolment earlier on. (HiCE-PopSocSci003)

(17) He asked the Ya-Na [appelation for a northern chief] to disregard rumours, circulating in the town that he would be deskinned as a result of the military take over, and reiterated that the NRC was not out to destool chiefs. (HiCE-PrPol102)

Apart from these there were only few other and those I found are likely idiosyncrasies as in (18) and (19).

(18) Surely as an old Achimotan you must be aware that some of our mates who could not make the grade were 'stopfordised'. (HiCE-LetEd052)
Achimota is one of the most prestigious schools in the country and $M r$. Stopford was a headmaster who obviously had a reputation to dismiss pupils considered to be not up to standard.

(19) It is not helpful to accuse a paper, which does not operate in such specialised field [agriculture], of having failed because of its inadequate study of his so-called 'cocoacracy'. ${ }^{4}$ (HiCE-LetEd095)

Phraseology is another area in which we find Ghanaianisms to abound. Interestingly, many of the items in this category seem to have been taken over directly from (learned) British English, without any sign of nativization as in (20) and (21), otherwise we would have expected an expression like Every Kofi, Kojo and Kwaku. On the other hand, formulaic expressions can seemingly also fall out of use, as with (22). There are five hits in the Letters to the editor in HiCE Ghana, but no instances were found in either ICE Ghana or GloWbE.

(20) At festivals, durbars, etc., where every Tom [,] Dick and Harry is enjoying himself, foreigners are not precluded from taking part in the dance. (HiCE-SkiHob001)

(21) This is to discourage every Tom, Dick and Harry from running for political office. (GloWbE GH G)

(22) KINDLY allow me a space in your paper to put the difficulties facing the kente [a type of cloth] weavers before the members of the National Liberation Council. (HiCELetEd107)

A quantitative analysis based on about 2,800 $(\sim 70 \%)$ of the previously attested Ghanaianisms can give us a first impression on how the lexicon has expanded over time in GhE and which wordformation processes are mainly at work. Figure 1 shows that the use of Ghanaianisms has increased considerably over two generations. In $\mathrm{HiCE}$ Ghana about 848 Ghanaianisms are found per million words (pmw); in the more recent corpus this figure stands at 1158, an increase of about $36 \%$. This, however, is not mirrored in the token figures, which have decreased. This may be explained by the different contents of the two corpora. In the early data, many of the texts included in the Humanities and Social Sciences sections address Ghanaian customs or cultural traditions so that there frequently are multiple instances of individual Ghanaianisms in a single text. On the other hand, hapax legomena - single instances of a type in the corpus - are quite frequent accounting 


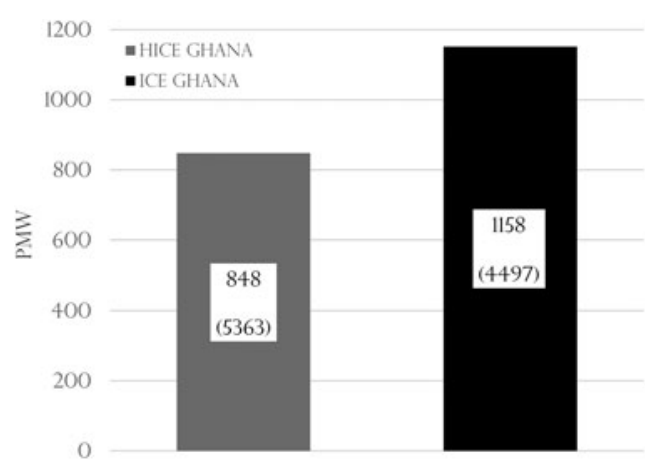

Figure 1: Types (tokens) of Ghanaianisms in HiCE Ghana and ICE Ghana

for 181 of a total of 620 types attested in either corpus. This can be explained by the comparatively small size of the corpora, particularly for lexical research. This is for example the case for jollof rice, a staple food in Ghana and akwaaba, which means 'welcome' in Akan.

Overall, items of English origin clearly dominate in the corpus data as can be seen in Figure 2. In the older corpus data more than $75 \%$ of all types are of English origin, Ghanaian items account for about $19 \%$ and both hybrids and foreign items are overall rather rare at just about $2.7 \%$ each. In ICE Ghana the figures are only marginally different. English items account for $74 \%$, those of Ghanaian origin for just over $20 \%$, hybrids for about $3.5 \%$ and foreign words for a mere $2.7 \%$. The figures reported by Dako (2003: 2) are as follows: about $60 \%$ of Ghanaianisms are of English origin, 30\% are Ghanaian and the rest are hybrid or foreign words. The reason for this is not completely clear, but I assume that this may be a sampling effect. Dako also included student writing as a source, whereas HiCE Ghana and the selected sections of ICE Ghana only contain printed material. Student writing may reflect a less formal style

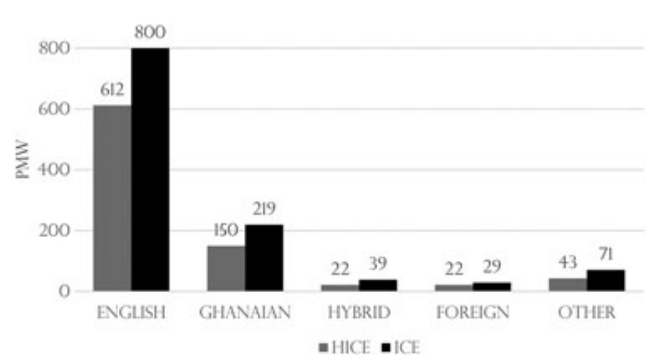

Figure 2: Types of Ghanaianisms by language of origin in HiCE Ghana and ICE Ghana and therefore include more ad-hoc formations and be more prone to structures being taken over from spoken registers.

Just focusing on the English items with regard to the word-formation processes that are used to create new lexemes, the corpus data suggests that Ghana does not behave in the same way as other postcolonial varieties. Biermeier (2008) compared word-formation in a number of varieties of Englishes around the world based on data from a set of ICE corpora. He claims that the most productive processes are compounding, conversion and derivation. ${ }^{5}$ Figure 3 shows the four major word-formation processes of the English items. ${ }^{6}$ By far the most frequent process is semantic shift, which accounts for about $45 \%$ of all types in both corpora. Compounding comes in second with about $29 \%$ in HiCE Ghana and $27.4 \%$ in ICE Ghana. Only about $8 \%$ of the items were created by derivation. The final category, multi-word expressions (MWE), contains what Dako (2001: 32) refers to as idiomatic formations such as just like that, meaning easily or without reason and phrasal and prepositional verbs as in (25). Both occur about equally frequently in the corpora and together make up another $18 \%$ of the items attested. At this stage, the stark discrepancy between the findings from Ghana and those of Biermeier (2008) cannot be explained straightforwardly and requires further research, e.g. by searching the corpora systematically for typical affixes used in the creation of new words. However, I am not sure that this will significantly change the current findings as during the compilation of HiCE Ghana I paid special attention to possible new derivations and noted down only very few, such as cocoacracy referred to in (19).

Turning to grammatical features, we can rely on Sey (1973: 26) who lists eleven features of ' $[\mathrm{g}] \mathrm{ram}$ matical deviant usage' and Huber \& Dako (2004)

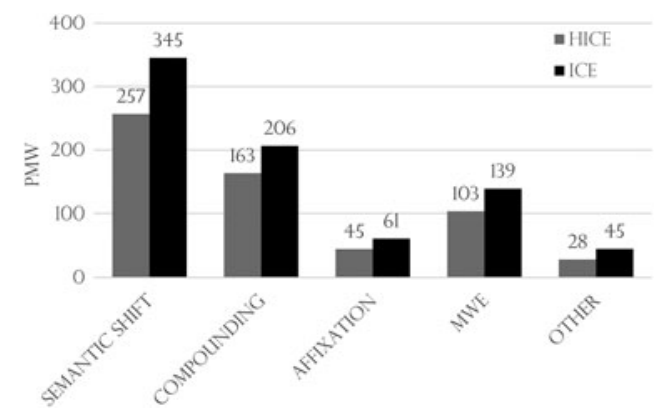

Figure 3: Types of word-formation for English words in HiCE Ghana and ICE Ghana 
as well as Huber (2012) who provide comprehensive summaries of typical Ghanaian variants. Many of these features cannot be analysed using written data only, such as tag questions or the way Yes/No questions are answered.

Within verb phrase grammar, a feature commonly mentioned for varieties of English in general and also for GhE is the overuse of the progressive aspect and its extension to stative verbs, as in (23) and (24). This feature is not mentioned in three of the earlier works on English in Ghana (Mensah, 1971; Sey, 1973; Tingley, 1981), but is found several times in HiCE Ghana, which suggests that it had at least some currency in the variety during its early nativization.

(23) By this time Kofi was finding the school a happy place. (HiCE-Novel009)

(24) I am therefore requesting you to effect the above correction without delay. (HiCEPrReg092)

Different strategies are found for phrasal verbs. It is a rather common phenomenon in GhE to add a particle where British English would not as in (25) or (26) or leave it out, as in (27).

(25) A form of entertainment in which once you pay in at the gate you are sure of getting at least three things [ ... ] (HiCE-AcHum018)

(26) About 6,500 seeds of the plant were sold out or distributed from Aburi in 1899. (HiCE-AcTech010)

(27) He would stop crying as soon as she picked him Ø. (HiCE-AcSocSci017)

There are numerous instances in both HiCE Ghana and ICE Ghana as regards the nonstandard usage of modal verbs. One of these is the use of will in contexts in which British English uses would as in (28) and (29). Sey (1973: 35) suggests that this may be because the past tense functions of modals are taught only relatively late, by which time the pupils have often developed fixed systems for the uses of present and past tense forms. This can also be observed with the other modal verbs, but appears most strongly for the will/would pair.

(28) But I will like to ask this question [ . . ] (HiCE-LetEd027)

(29) I personally will be very much satisfied if the Government will issue a statement either condemning or commending the activities of Jeafan and Nzereaibe. (HiCE-LetEd098)

Example (29) also shows another frequent feature found in HiCE Ghana. There is a strong tendency to overuse collocations such as condemning and condoning, tall and huge or condoned and connived as a stylistic means.

Within the noun phrase typical features are the nonstandard use of articles, which may be left out as in (30) or added in unexpected positions as in (31).

(30) When the visitor wants to take $\varnothing$ photograph of special objects or personages, it is much appreciated if permission is first sought. (HiCE-SkiHob001)

(31) In the Elmina Castle the slave market is beneath the chapel. (HiCE-AcHum002)

Huber \& Dako's (2004: 860) claim that the 'omission of an article before majority (of)/minority (of) can be described as default usage' as in (32) cannot be confirmed by the data from the two corpora. In HiCE Ghana about $87 \%$ (53 of 61 tokens) have an article as in (33); in ICE Ghana the figure is only marginally lower at $83 \%$ ( 29 of 35 tokens).

(32) This, he said, is the general view of Ø majority of Ghanaians $[\ldots]$ (HiCE-PrPol166)

(33) $[\ldots]$ but that she regarded the white minority in Rhodesia as brothers and sisters whose interests must be safeguarded. (HiCEPrEd065)

\section{Discussion}

GhE is not a prototypical variety in the sense of Schneider's (2007) Dynamic Model (most notably because of the absence of a sizeable STL strand). The model provides a good framework for capturing the linguistic developments during the nativization phase, but cannot explain some of the processes I outlined above. As predicted, there has been large-scale lexical expansion, both regarding the number of Ghanaianisms as such and their frequency of use. However, at least in the written data available, the processes that Ghanaians employ to increase the word-stock are different from previous descriptions for both Ghanaian and other Englishes, while at the same time homogenous across the two corpora. The grammatical features have so far not been analysed quantitatively, but the first findings outlined suggest that some features may have been used much more systematically at an earlier stage than previously suggested in the research literature on GhE. A recent adaption of Schneider's model, the 'Extra- and Intraterritorial Forces Model', proposed by Buschfeld \& Kautzsch (2017), may help explain certain patterns found in Ghanaian English even better. They suggest that both 
postcolonial and non-postcolonial varieties (such as English in Korea; Rüdiger, 2014) develop in similar ways and during every stage of their development are influenced by factors such as globalisation (also cf. Mair, 2013), language policies or sociodemographic background. In the context of Ghanaian English, particularly the two latter may be important intraterritorial forces. Brato (in prep.) relates the linguistic findings more strongly to demographics considering census data for population developments and education. There is, for example, a clear dominance of writers with an Akan L1 background in HiCE Ghana. This group constitutes about $45 \%$ of the population, but accounts for an estimated $75-80 \%$ of all texts for which we know the author. As the early schools were also mainly located in Akan-speaking areas and Akans were strongly overrepresented in official positions, it seems likely that these speakers - in the absence of an STL strand - served as a (covert) 'role model' for other Ghanaians learning English. This may have led to GhE being characterised mainly by Akan features, but of course more systematic research in this respect is warranted. Together with other factors, such as internal (Northerners moving South) and external migration patterns (such as to and from Nigeria), greater media exposure and language attitudes (e.g. Ofori \& Albakry, 2012) the Akan dominance has contributed to the specific linguistic situation in Ghana. Factoring in these 'forces' may help in explaining (putative) deviations from the developmental path suggested in the Dynamic Model, such as the emergence of the 'Locally acquired foreign accent' phenomenon (Shoba, Dako \& OrfsonOffei, 2013) as early as the transition between phases 3 and 4, although such social differentiation is one of the key elements indicating that a variety has progressed to phase 5 .

\section{Conclusion}

The empirical, data-based study of linguistic developments in the evolutionary cycle from a historical angle is one of the growing areas in the research on postcolonial Englishes, which can be seen by the various corpora that have been created recently or are currently in the making. The two approaches to corpus compilation outlined in this paper complement each other. The diachronic corpora following the Brown design focus on comparability across varieties of English at specific points in time. The approach taken in HiCE Ghana was different in that the focus is rather on being able to test the predictive value of the Dynamic model for a single variety and over a single evolutionary phase based on a real-time comparison of empirical data and propose adaptations where it seems appropriate and necessary. At the same time, there is certainly potential to apply the HiCE Ghana design to varieties of English in other parts of Africa or the world, particularly those with a similar linguistic and socio-political history, such as Nigeria, Tanzania or Kenya, and thus create comparable corpora for cross-varietal analyses. These countries became independent and progressed to the nativization phase at around the same time and there is no significant STL strand. Modifications may be desirable or needed depending on the linguistic situation of a variety, e.g. to represent major L1s (as in Nigeria), or because of the sparsity of data available for relevant timeframes or categories.

\section{Notes}

1 In both sources 'literacy' means having a basic understanding of the English language and being able to "read and write a simple statement with understanding" (Ghana Statistical Service, 2012: xi). Literacy greatly varies between this rather basic and a native competence.

2 'Historical corpus' is defined here as a corpus consisting of data from one point in time (or a short timespan) in the past (such as HiCE Ghana or Phil-Brown). 'Diachronic corpus' refers to a corpus which from its outset includes several snapshots of historical states (such as the Diachronic Corpus of Hong Kong English).

3 http://www.oed.com/view/Entry/240646

4 Cocoacracy presumably describes the importance of cocoa in the Ghanaian economy, but the author does not make this clear.

5 Of course, analysing semantic shifts requires a different approach than that taken by Biermeier, as they cannot be searched for in the systematic way as compounds or derivations.

6 The other word-formation processes (conversion, reiteration, shortening, plural formation and a couple of items which could not be assigned any of the other categories) combined account for only about $4 \%$.

\section{References}

Apponsah, K. 1968. 'African writers must be up and doing.' The Evening News, February 20, 4.

Biermeier, T. 2008. Word-Formation in New Englishes: A Corpus-Based Analysis. Münster: LIT.

Biewer, C. Bernaisch, T. Berger, M. \& Heller, B. 2014. Compiling The Diachronic Corpus of Hong Kong English (DC-HKE): Motivation, Progress and Challenges. Nottingham, 30/04.

Blench, R. 2006. 'A dictionary of Ghanaian English.' Online at $<$ http://www.rogerblench.info/Language/English/Ghana \%20English\%20dictionary.pdf $>$ (Accessed July 13, 2016). 
Borlongan, A. M. \& Dita, S. N. 2015. 'Taking a look at expanded predicates in Philippine English across time.' Asian Englishes, 17(3), 240-7.

Brato, T. in prep. 'Locating Ghana in the Extra- and Intraterritorial Forces Model.'

Buschfeld, S. \& Kautzsch, A. 2017. 'Towards an integrated approach to postcolonial and non-postcolonial Englishes.' World Englishes, 36(1), 104-26.

Dako, K. 2001. 'Ghanaianisms: Towards a semantic and formal classification.' English World-Wide, 22(1), 23-53.

Dako, K. 2003. Ghanaianisms: A Glossary. Accra: Ghana University Press.

Davies, M. \& Fuchs, R. 2015. 'Expanding horizons in the study of World Englishes with the 1.9 billion word Global Web-based English Corpus (GloWbE).' English World-Wide, 36(1), 1-28.

Francis, W. N. \& Kučera, H. 1964. A Standard Corpus of Present-Day Edited American English, for Use with Digital Computers (Brown): Brown University, Providence, Rhode Island.

Fuchs, R. \& Gut, U. 2015. 'An apparent time study of the progressive in Nigerian English.' In P. C. Collins (ed.), Grammatical Change in English World-Wide. Amsterdam: John Benjamins, pp. 373-87.

Ghana Statistical Service. 2012. 2010 Population \& Housing Census: Summary Report of Final Results. Online at $<$ http://www.statsghana.gov.gh/docfiles/2010phc/ Census2010_Summary_report_of_final_results.pdf $>$ (Accessed July 13, 2016).

Gordon, E. Maclagan, M. \& Hay, J. 2007. 'The ONZE Corpus.' In J. C. Beal, K. P. Corrigan \& H. L. Moisl (eds.), Creating and Digitizing Language Corpora: Volume 2: Diachronic Databases. Basingstoke: Palgrave Macmillan, pp. 82-104.

Greenbaum, S. 1991. 'ICE: The International Corpus of English.' English Today, 7(4), 3-7.

Huber, M. 2012. 'Ghanaian English.' In B. Kortmann \& K. Lunkenheimer (eds.), The Mouton World Atlas of Variation in English. Berlin: Mouton de Gruyter, pp. 382-93.

Huber, M. 2014. 'Stylistic and sociolinguistic variation in Schneider's Nativization Phase: The case of Ghanaian English.' In S. Buschfeld, M. Huber, T. Hoffmann \& A. Kautzsch (eds.), The Evolution of Englishes: The Dynamic Model and Beyond. Amsterdam: John Benjamins, pp. 86-106.
Huber, M. \& Dako, K. 2004. 'Ghanaian English morphology and syntax.' In E. W. Schneider, K. Burridge, B. Kortmann, R. Mesthrie \& C. Upton (eds.), A Handbook of Varieties of English: A Multimedia Reference Tool. Berlin: Mouton de Gruyter, pp. 854-65.

Kachru, B. B. 1985. 'Standards, codification and sociolinguistic realism: The English language in the outer circle.' In R. Quirk \& H. G. Widdowson (eds.), English in the World: Teaching and Learning the Language and Literatures. Cambridge: Cambridge University Press, pp. 11-30.

Kirby, J. P. 1998. A North American's Guide to Ghanaian English. Tamale: Tamale Institute of Cross-Cultural Studies.

Mair, C. 2013. 'The World System of Englishes: Accounting for the transnational importance of mobile and mediated vernaculars.' English World-Wide, 34(3), 253-78.

Mensah, A. N. 1971. 'The language of Ghanaian newspapers.' Legon Observer, October 22, 6-12.

Mukherjee, J. \& Gries, S. T. 2009. 'Collostructional nativisation in New Englishes: Verb construction associations in the International Corpus of English.' English World-Wide, 30(1), 27-51.

Ofori, D. M. \& Albakry, M. 2012. 'I own this language that everybody speaks: Ghanaians' attitude toward the English language.' English World-Wide, 33(2), 165-84.

Rüdiger, S. 2014. 'The nativization of English in the Korean context: Uncharted territory forWorld Englishes.' English Today, 30(4), 11-4.

Schneider, E. W. 2007. Postcolonial English: Varieties Around the World. Cambridge: Cambridge University Press.

Sey, K. A. 1973. Ghanaian English: An Exploratory Survey. London: Macmillan.

Shoba, J. A. Dako, K. \& Orfson-Offei, E. 2013. "Locally acquired foreign accent" (LAFA) in contemporary Ghana.' World Englishes, 32(2), 230-42.

Simo Bobda, A. 2000. 'The uniqueness of Ghanian English pronunciation in West Africa.' Studies in the Linguistic Sciences, 30(2), 185-198.

Tingley, C. 1981. 'Deviance in the English of Ghanaian newspapers.' English World-Wide, 2(1), 39-62.

Van Rooy, B. \& Piotrowska, C. 2015. 'The development of an extended time period meaning of the progressive in Black South African English.' In P. C. Collins (ed.), Grammatical Change in English World-Wide. Amsterdam: John Benjamins, pp. 465-83. 